\title{
Relationship between Team Conflict and Performance in Green Enterprises: A Cross-Level Model Moderated by Leaders' Political Skills
}

\author{
Yanhong Tu $\mathbb{D}^{1}$ and Leilei Zhang $\mathbb{D}^{2,3}$ \\ ${ }^{1}$ Business School, Hunan University of Technology, No. 88, Taishan West Road, Zhuzhou, Hunan 412007, China \\ ${ }^{2}$ Business School, Zhengzhou University, Zhengzhou 450052, China \\ ${ }^{3}$ School of Politics and Public Administration, Zhengzhou University, No. 100 Science Road, Zhengzhou, Henan 450052, China
}

Correspondence should be addressed to Leilei Zhang; eric_zhang@hnu.edu.cn

Received 14 November 2020; Revised 20 December 2020; Accepted 25 January 2021; Published 8 February 2021

Academic Editor: Dan Selisteanu

Copyright (c) 2021 Yanhong Tu and Leilei Zhang. This is an open access article distributed under the Creative Commons Attribution License, which permits unrestricted use, distribution, and reproduction in any medium, provided the original work is properly cited.

\begin{abstract}
It is evident that, being a member of the organization, the team has to cue the influx of the green management concepts. This study focuses on the aspect of team management in green enterprises. Applying leadership theory to sample green enterprises, this paper proposes that political skills of team leadership have moderating effects on the relationship between team conflict (relationship conflict and task conflict) and performance at both the individual and team levels. Empirical data were collected from 85 dyads of leaders and team members in 36 green enterprises in China. It was found that the leaders' political skills weakened the negative effects of relationship conflict on individual performance and team performance. Further, leaders' political skills strengthened the positive effects of task conflict on individual and team performance. The results of this study deepen the cognition of two types of team conflict in theory and provide theoretical guidance for green enterprises in carrying out effective team conflict management and practical political skills training for leaders.
\end{abstract}

\section{Introduction}

Green enterprises are part of a contemporary trend toward sustainable development in modern enterprise development. Innovation systems are necessary for green enterprises to promote an organic integration and coordinated development of marketization, knowledge, and ecology $[1,2]$. The development of green enterprises must extend the characteristics of ecological processes to enterprises. Green enterprises should bear ecology and economics in mind, controlling pollution and husbanding resources in all aspects of business operation, which often involves complex decision-making [3, 4]. For example, green enterprises must balance efficiency and fairness, economic benefit and environmental protection, and corporate interests and social evaluation. Some members are more motivated to perform environmental tasks, where it pays to be green, but others may be more motivated to perform economic tasks [5]. Thus, more conflicts may arise within teams in green enterprises relative to other conventional enterprises, especially in terms of green decision-making or the execution of green strategies. Conflict management thus plays an important role in green enterprises.

Here, team conflict refers to team members' perceptions of disharmony or contradiction between each other [6]. In green enterprises, the contradiction between economic benefits and environmental benefits is most likely to lead to team conflicts. The team in the green enterprise is often responsible for analyzing, planning, implementing, controlling, and coordinating the enterprise action and making it conform to the environmental strategy of the enterprise. Therefore, it is a common phenomenon that teams in green enterprises suffer from the ideological conflicts about economic efficiency and green decision-making. On the one 
hand, teams in green enterprises are burdened with the responsibility and obligation of formulating environmental business strategies and improving the environmental processes in organizations [7]. Consequently, there may be much conflict of attitudes and green decisions in teams. On the other hand, team in green enterprises usually uses recombinant ability to adopt explorative behaviors and combines previous knowledge to establish green strategies [8]. In the processes of team recombinant, different ideas or solutions may come into being and may induce team conflict [9]. More importantly, green technologies play an important role in green enterprises' green strategies, and Orsatti and Pezzoni [8] have verified that green technologies were almost generated by creative teams. Therefore, teams in green enterprise not only undertake the important task of enterprise development, but also accumulate the risk of fierce team conflict. For example, some recent studies have suggested that team resilience helps a lot for a green enterprises' green sustainable development [7]. The above aspects all highlight the necessity and importance of team conflict management in green enterprises.

Team conflict in green enterprises includes task and relationship conflict. Task conflict refers to disputes among team members about the choice of task completion scheme, while relationship conflict comes from interpersonal friction among team members that has no direct relationship with team function or goals [10]. The traditional view holds that conflict is an obstacle to team development, but close study of human relationships has indicated that it is inevitable, and team conflict may have positive effects. Empirical studies have shown that team conflict can have a negative impact on output, but no clear relationship between team task conflict and performance has been determined. It is commonly thought that team task conflict has positive effects on team performance and team innovation through the development of improved efficiency in information processing, team creativity, and team problem-solving $[6,11]$. However, it has also been suggested that team task conflict may enhance team relationship conflict, which might adversely affect team performance by reducing the efficiency of informationprocessing mechanisms among team members [12].

The inconsistency of the results of prior research indicates that situational variables strengthen or inhibit the impact of team task conflict and relationship conflict on performance. Conflict is a common and inevitable phenomenon in team work, especially in green enterprises. Thus, it is of great importance to explore the links between team task/relationship conflict and performance, including the boundaries of these links. Few studies have examined how the positive effects of task conflict could be enhanced and the negative effects of relationship conflict could be reduced. In recent years, scholars have begun to pay attention to moderating factors between team conflict and team output in different aspects, such as the interactions between team members, team management, team members' emotions, and other aspects [13]. In practice, the leadership and coordination ability of team leaders are very important to the management of team conflict in green enterprises due to their particularity. According to the leadership theory, leaders can effectively take their advantages to influence subordinates' attitudes and behaviors by using abilities, skills, talents, or professional knowledge that their subordinates have recognized, so as to achieve excellent performance of the organization or team [14]. A large number of scholars have discussed the important role of leadership in organization and team management from the theoretical perspectives of leadership traits, leadership behaviors, and leadership contingency [13]. With the increasing uncertainty in organizations especially in green enterprises, political behavior plays an increasingly important role, and leaders' political skills become important skills to effectively manage organizations and teams [7]. The political skills of leaders are indispensable for coordinating inconsistent goals, tasks, needs, and interests of teams in green enterprises. Team leaders have an important influence on all aspects of team activities, and their political skills can help resolve team conflicts, especially in team conflict management for green enterprises to formulate a sustainable business strategy [7]. However, discussion of the role of leaders' political skills is still lacking. Therefore, this paper uses leaders' political skills as a moderator to investigate its effect on team conflict management.

Task conflict is related to cognitive differences between team members due to inconsistency in views, and relationship conflict is related to emotional differences caused by interpersonal discussions of weariness or dislike [15]. Therefore, task conflict and relationship conflict can affect both team and individual performance. However, existing studies pay greater attention to the impact of conflict on team performance, ignoring the effects of conflicts on individual performance. Team members respond differently to team situations, so team performance cannot be equated with individual performance. In fact, high-performance members can inhibit overall team performance in certain cases [16]. To properly assess the role of team task conflict and relationship conflict in performance, it is necessary to distinguish the effects of team and individual performance at both the team and individual levels. From the literature aforementioned, we found that the existing studies on team conflict focus on traditional performance with few studies on green performance especially in green enterprises. For green enterprises, performance not only includes the traditional understanding of performance, but also cares about the interactions between the environmental dimension and business [17]. In addition to achieving the demanding profit rate or income growth rate in traditional performance appraisal, the implementation of greenification and sustainable development is also an important part of green enterprise performance. The performance appraisal of green enterprises often presents characteristics such as high production cost, green quality assurance, high requirement of $R \& D$ capability, and requirements of green supply chain. This paper therefore constructs a cross-level model of the effects of leadership political skills on team conflict and green enterprises' performance at both the team and individual levels. This paper is thus able to enrich the study of team conflict management from a leadership perspective. The results extend team-individual cross-level conflict theory 
and provide specific guidance on how to promote the positive role of team conflict and to restrain its negative effects in the practice of green enterprise management.

\section{Background and Hypotheses}

2.1. Relationship between Team Task Conflict, Individual Performance, and Team Performance. The individual performance of team members describes how individual members are evaluated by their team leaders and peers and the degree to which individual production records meet or exceed team or organizational standards [18]. Individual performance is positively influenced by team task conflict. Authoritative studies (such as Wanous and Youtz [19]) have found that inconsistency in opinions among team members can stimulate them to produce novel plans or engage in creative thinking and other cognitive activities. Task conflict can create novel inspiration and lead to valuable decisions that promote individual performance [20]. Putnam reported that team task conflict helps members identify and better understand issues related to task completion and encourages them to develop new ideas and methods, thus improving the quality of their decision-making [21]. Fiol suggested that when team members differ in their understanding of taskrelated matters, their ability to learn and accurately assess the situation will be improved [22]. Differing views and perspectives for team task conflict can encourage team members to obtain additional information, think more deeply about different viewpoints and perspectives, and put forward more unique ideas [23]. However, for teams with low amounts of task conflict, team members become more committed to maintaining consistency with others, ignoring differences in views between members, making it difficult to improve the quality and quantity of team decisions, and limiting the ability to obtain the most efficient individual performance [24].

Hypothesis 1 . Team task conflict is positively correlated with team members' individual performance.

Team performance describes the ability of a team's production output to meet or satisfy established performance standards [25] including the needs of environment development [7]. To meet team performance standards, team members must evaluate the status quo, understand their tasks, and propose solutions based on their own and their teammates' knowledge, views, and abilities, with the ultimate goal of solving problems [26]. Team task conflict promotes the critical evaluation of problem-solving by team members and reduces the team's collective thinking by increasing thoughtful thinking and improving alternatives [27]. Team task conflict allows team members to identify and discuss different perspectives and to improve their understanding of their tasks, which allows them to develop more thorough assessments of the performance standards that the team needs to achieve, thereby producing high-quality decisions and improving team members' acceptance of collective decisions, which in turn promote improved team performance [28]. Team task conflict also gives team members a greater opportunity to express their views and propose solutions, encourages them to comprehensively evaluate all alternatives, and respects their positions and views, enabling an enhancement of team members' commitment to their tasks [29]. Task commitment helps intensify team members' initiative for participating in team work and has a stimulant effect on team performance.

Hypothesis 2. Team task conflict is positively related to team performance.

2.2. Relationship between Team Relationship Conflict, Individual Performance, and Team Performance. Team relationship conflict negatively affects team members' individual performance. First, increased team relationship conflict is usually accompanied by negative communication and expression, unwillingness to cooperate, and negative psychological emotions of anger, distrust, fear, and depression [18]. These negative emotions seriously affect team members' individual efficiency and working enthusiasm, reducing their individual performance. The content involved in team relationship conflict is not related to team tasks. It is easy to cause negative emotions among team members and seriously threaten their self-identity and their sense of selfworth [30]. According to threat stiffness theory, when people feel threats from the outside world, they tend to stagnate, reduce, or withdraw input [31]. Therefore, in conditions of high relationship conflict, team members tend to adopt passive sabotage behaviors that lead to lower individual performance. Second, following the theory of limited attention resources, team members' attention resources in the team are allocated between work-related and unrelated transactions [32]. When tension, friction, and emotional disharmony are common among team members, each team member allocates additional resources to deal with these non-work-related matters and can only devote a small amount of resources to discuss problem solutions. Therefore, team relationship conflict reduces individual performance by diverting work attention.

Hypothesis 3. Team relationship conflict is negatively correlated with individual performance.

Team relationship conflict hinders positive interaction among team members. With the increase of the relationship conflict, team members tend to attribute differences in views and problem solutions to their interpersonal relationship friction, and they adopt a hostile attitude to others' suggestions, especially critical ones [33]. This makes them unwilling to accept the opinions of others or to draw inspiration from them, which limits the improvement of team performance. Second, team relationship conflict can easily cause negative emotions among team members. Guided by their negative emotions, team members can become narrowminded and critical. They may not only ignore the information and resources that can impact team performance, but also find it difficult to integrate resources and information into the team effectively, often prohibiting them from making the optimal decision [34], and they may even make the wrong decisions, which can affect improved team 
performance. Third, team relationship conflict limits the team's ability to process information, and team members are driven to spend additional time and energy in dealing with their relationships and to neglect the development of solutions to team problems [35]. Fourth, team relationship conflict enhances stress and anxiety among team members and hinders their cognitive ability, making it difficult to put forward better solutions to achieve team goals and objectively reducing team performance.

Hypothesis 4. Team relationship conflict is negatively correlated with team performance.

\subsection{Moderating Effects of Team Leader Political Skills on the Relationship between Task Conflict and Performance.} Ferris described political skills as the means by which individuals can understand others effectively at work and use this understanding to influence others and enable them to support themselves to achieve individual and organizational goals [35]. Political skills are actualized in the interaction and mutual influence between individuals and other individuals, groups, or organizations, and they are an organic combination of individual social effectiveness and interpersonal interaction capabilities. Following previous studies, Treadway proposed that leaders' political skills are key to improving team and organizational performance [36] and presented three characteristics that leaders with high political skills possess: first, they use suggestive behavior flexibly, and they identify and classify other people's motivations in a timely and accurate manner through observation; second, they are good at influencing others and adjusting their attitudes and behaviors to changing environments; and third, they are good at strengthening their social capital and employing scarce resources through the establishment and management of interpersonal networks [37]. Team leaders' political skills involve their social acumen, interpersonal influence, network operations, and sincere performance, which affect team members, formulate work plans, and effectively manage teams. Team leaders with high-level political skills can flexibly adjust their team management strategies according to the dynamics of the given team environment and the interactions among team members [38].

The political skills of team leaders can effectively support the management of task conflicts. Social impact theory indicates that team leaders with high levels of political skills can get along well with team members and help them save face in team interactions. They can gain the trust and higher evaluation of team members more easily and achieve effective management by influencing team members [39]. Team leaders' political skills have an important impact on the effective management of team conflict. Studies have shown that too many task conflicts can increase the cognitive load of team members, distract them, and even cause team relationship conflicts, which are bad for both team and individual performance [40]. Team leaders with high political skills can actively adjust the team atmosphere in relation to the state of the interactions and the degree of conflict between team members. First, they can influence and control the attitudes and behaviors of team members and maintain a reasonable level of task conflict to promote its positive impact on individual and team performance. Second, when faced with excessive team task conflicts, team leaders with high political skills can persuade their team members to regard differing views and ideas as opportunities to learn, using social sensitivity, interpersonal influence, and sincerity. This can help guide team members to integrate a range of information and provide better feedback. In addition, team leaders that have high political skills can also enable the establishment of an atmosphere of trust in a team because they can prevent the team from mistakenly attributing task conflicts to interpersonal threats and team task conflicts from becoming team relationship conflicts that can harm team performance [41]. Additionally, the political skills of team leaders have not only a positive impact on the trust of team members but also a negative impact on their cynicism [37]. Team leaders with high political skills can understand the work motivation of team members in relation to their different characteristics. On this basis, leaders can classify team members according to the differences in their characteristics and adopt appropriate communication styles and strategies to specifically increase their trust in their leaders [42], encourage them to adopt a positive attitude toward team task conflicts as the effort of team members to achieve compatible goals, promote the application of individual effort to team and individual goals [43], and reinforce the positive impact of team task conflict on individual and team performance.

Hypothesis 5. Team leaders' political skills moderate the positive impact of team task conflict on individual performance: the stronger the political skills, the stronger the positive impact of team task conflict on individual performance.

Hypothesis 6. Team leaders' political skills moderate the positive impact of team task conflict on team performance: the stronger the political skills, the stronger the positive impact of team task conflict on team performance.

\subsection{Moderating Effects of Team Leader Political Skills on the Relationship between Relationship Conflict and Performance. Employment of an effective conflict management strategy or reduction of the relationship between team relationship conflict and the negative emotions of team members can limit the negative impact of team relationship conflict on individual and team performance [6]. Studies have shown that leaders play an important role in choosing effective methods of managing conflict and weakening the negative side of relationship conflicts [13]. As noted, leaders with high political skills are adept in the flexible use of suggestive behaviors and can recognize and classify others' motivations in a timely and accurate fashion through observation. They can influence others and adjust their own attitudes and behaviors in terms of dynamic environments: team leaders with high political skills can shore up their social capital and}


resources through the effective establishment and management of interpersonal networks [37]. The above characteristics indicate that team leaders with high political skills can play an important role in suppressing the negative effects of team relationship conflict on individual and team performance.

At the individual level, leaders with high levels of political skills can get along well with team members and help save face in team interactions. They can gain the trust of team members more easily [44]. First, where team leaders have high political skills, team members are more willing to communicate with them and vent their negative feelings, which is conducive to their work. Leaders with high political skills are good at observing members' behaviors and emotions and are able to adopt effective means of relieving the negative emotions, such as anger, distrust, fear, and depression that are caused by relationship conflicts among members with different characteristics [44]. Leaders with high levels of political skills can help team members find ways to relieve or eliminate negative feelings to improve their individual efficiency, enthusiasm for work, and individual performance. Leaders with high political skills can reduce the negative impact of relationship conflicts on team members' individual performance. Second, when the selfidentity and self-worth of team members are threatened, leaders with high political skills can help members restore their self-esteem by making use of their interpersonal influence, which also aids in the restoration of their enthusiasm for work [43]. Leaders with high political skills can adopt appropriate communication styles in response to members' different personalities to enhance their perception of the political skills of leadership, increase their trust in leadership, aid them to respond to team relationship conflict with a positive attitude and regard it as a simple misunderstanding encountered while achieving compatible goals, and enable them to shift their attention from dealing with interpersonal conflicts to work tasks [45]. Thus, the negative impact of team relationship conflict on individual performance is reduced.

At the team level, leaders with high political skills have a high sense of social acuity, and they both recognize the negative feelings of team members and hostile relationships among them and take timely and effective communication and facilitation measures to minimize the impact on team performance $[7,13]$. First, leaders with high political skills exert a strong interpersonal influence, leading their teams to correctly appraise their different opinions, which can help them approach these opinions rationally and guide them to accepting others' opinions to bring inspiration and new thought that improves team performance. Second, leaders with high political skills have strong abilities in network operation [45]. They make use of their influence and resources to focus the attention of team members on team tasks, guide team members to avoid narrow mindedness, attach importance to information and resources that can impact team performance, and effectively integrate resources and information to make optimal decisions that can solve team problems [46]. Third, leaders with high political skills can build an atmosphere of trust and harmony, reduce tension and pressure caused by relationship conflict among team members, and enable team members to use their cognitive ability effectively to contribute to team decisionmaking. Team leaders with high political skills can also unblock communication channels within teams [47] to promote the effective circulation of information and resources among different members and guide people to seek new information resources from existing ones, help their team reach the best solution to their problems, and promote team performance [48]. Accordingly, we propose the following research hypotheses.

Hypothesis 7. Team leaders' political skills moderate the negative impact of relationship conflict on individual performance: the stronger the political skills, the weaker the negative impact of team relationship conflict on individual performance.

Hypothesis 8. Team leader political skills moderate the negative impact of team relationship conflict on team performance: the stronger the political skills, the weaker the negative impact of team relationship conflict on team performance.

The theoretical model of this research is presented in Figure 1.

\section{Materials and Methods}

3.1. Sample and Procedure. Using a multisource, multilevel survey design, we collected data from 500 members of 120 work teams in 36 green enterprises in four types of businesses in China, including enterprises making food, electronic technology, motor vehicles, and chemical products. We invited attendee companies at a green economy forum at a major research institution in the south of China, to participate in the study. Once they had agreed, the companies identified teams that were available to complete the survey. The authors distributed and collected paper copies of the questionnaires either on-site or over network communications during working hours. The responses were voluntary, and the confidentiality of the participants was assured. The members of the participating work groups were in customer service, marketing, $\mathrm{R} \& \mathrm{D}$, and top management. To minimize potential common method bias, we collected perception data (e.g., team tasks and friendship conflicts and leaders' political skills) from team members and data on team and individual performance from the team leaders' performance files. Team members described their perceptions of their leaders' political skills, task relationships, and relationship conflicts. Unless otherwise indicated, all continuous variables were measured on a 5-point Likert scale ( $1=$ strongly disagree; $5=$ strongly agree $)$.

We distributed surveys to 120 teams, of which 105 (87.50\%) provided responses, including 454 team members. Team size ranged from 3 to 10 people, with an average of about 6 . Excluding teams with fewer than three responses and eliminating questionnaires with incomplete information resulted in a valid team response rate of $71.00 \%$. This represented 85 team leaders and 414 members. These teams 


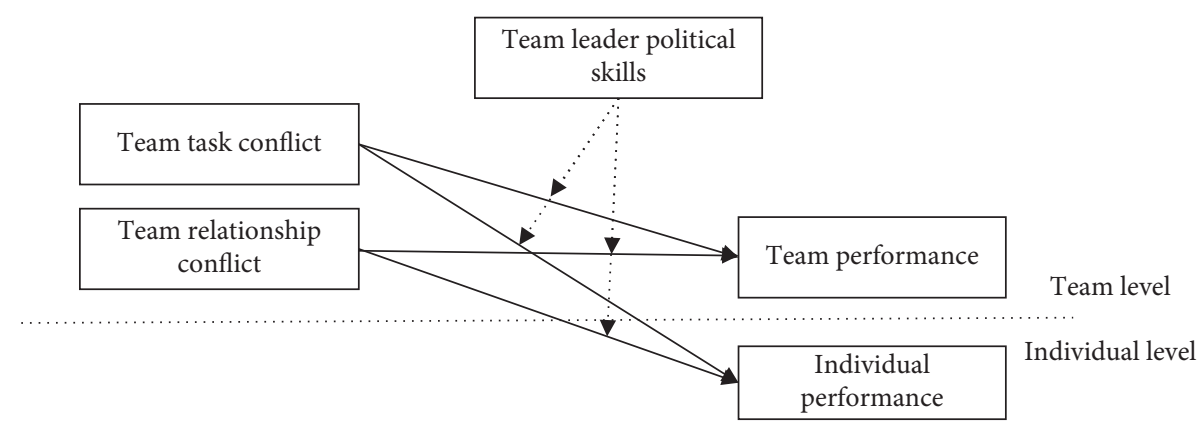

FIGURE 1: Cross-level model of interactions between team conflict and performance.

were from several regions of China (Beijing, Guangdong, Shanghai, Zhejiang, Hubei, Jiangxi, and Hunan), and 32.94\% of the sample was from food enterprises, $28.24 \%$ was from electronic technology enterprises, $21.18 \%$ was from motor vehicle enterprises, and $17.64 \%$ was from daily chemical products enterprises.

3.2. Measures. Using the back-translation procedure [49], we first translated all English-language measures into Chinese and then independently translated them into English to guarantee equivalency of meaning. We recruited $30 \mathrm{MBA}$ students and $6 \mathrm{PhD}$ students to ensure the content validity of our questionnaires. The survey was revised in response to their feedback and suggestions.

(i) Team task conflict: a four-item scale developed by Jehn was used to measure team task conflict [50]. Team task conflict is a team-level variable, so it was completed by team members to describe their own perceptions, and the responses were aggregated at the team level in the analysis.

(ii) Team relationship conflict: a four-item scale developed by Jehn was used to measure team relationship conflict [18]. After the confirmatory factor analysis, we found that a single-factor model had good fit, $\chi^{2} / \mathrm{d} f=1.965, \mathrm{GFI}=0.942, \mathrm{SRMR}=0.050$, RMSEA $=0.071$, TLI $=0.929$, and CFI $=0.950$. This indicates that the team relationship conflict scale had good construct validity. Team relationship conflict was also assessed at the team level. The scale was completed by team members to describe their own perceptions, and the responses were aggregated at the team level in the analysis.

(iii) Leader political skills: a scale of political skills developed by Ferris et al., including the four dimensions of social acuity, interpersonal influence, interpersonal network ability, and performance sincerity [51], was used. Confirmatory factor analysis shows that the single-factor model had a good fit, $\quad \chi^{2} / \mathrm{d} f=2.23, \quad \mathrm{GFI}=0.942, \quad \mathrm{SRMR}=0.049$, RMSEA $=0.063$, TLI $=0.936$, and CFI $=0.963$. To ensure objectivity, the 18-item scale was completed by team members to describe their own perceptions.

(iv) Team performance and individual performance: we used time lag objective data to measure team and individual performance including incubators of green business and environment concerns. Three months after the team members had completed the political skills and relationship conflicts questionnaires, we collected objective data on team and individual performance from team performance files. To facilitate uniformity in the data analysis, we averaged performance data for multiple teams in each company and for multiple members of each team. Then we coded team (individual) performance within the range 1-5 according to differences in team (individual) mean (1, three standard deviations below the mean; 2 , one standard deviation below the mean; 3 , equal to the mean; 4 , one standard deviation above the mean; and 5, three standard deviations above the mean).

(v) Control variables: following the previous research, in addition to measuring these key variables, we also controlled variables that affect team and individual performance at both the individual and team levels. Control variables at the individual level were gender, tenure, and education; at the team level, they were team size and team type. To ensure study validity, this paper controls the role of task conflict in testing the effects of relationship conflict on performance, and it controls the role of relationship conflict for testing the effects of task conflict on performance.

3.3. Data Aggregation. Task conflict and relationship conflict were measured based on the perceptions of team members. This enabled us to collect data at the individual level. This entails the necessity of analyzing the consistency of team members' perceptions before the data analysis to determine whether individual-level data could be aggregated to the team level. We adopted the method developed by James et al. to calculate pairs of variables from the members of each team [52]. The median of $R_{\mathrm{wg}(j)}$ index for team task conflict and team relationship conflict was 0.91 and 0.89 , so the variables exhibit good internal consistency and can be aggregated at the team level [53].

\section{Results}

4.1. Descriptive Statistics and Correlation Analysis. Table 1 shows the means, standard deviations, and correlation coefficients for all variables. Results at the team level 
TABle 1: Means, standard deviations, and correlations.

\begin{tabular}{|c|c|c|c|c|c|c|c|c|}
\hline Variables & Mean & SE & Max & Min & 1 & 2 & 3 & 4 \\
\hline \multicolumn{9}{|l|}{ Team level } \\
\hline Task conflict & 3.22 & 0.64 & 1.56 & 5.00 & 1 & & & \\
\hline Relationship conflict & 2.49 & 0.75 & 1.20 & 4.00 & $-0.21^{*}$ & 1 & & \\
\hline Team performance & 3.59 & 0.71 & 1.00 & 5.00 & $0.30^{*}$ & $-0.33^{* *}$ & 1 & \\
\hline Leader political skills & 3.65 & 0.90 & 1.00 & 5.00 & $0.37^{* *}$ & $-0.66^{* *}$ & $0.38^{*}$ & 1 \\
\hline \multicolumn{9}{|l|}{ Individual level } \\
\hline Individual performance & 4.42 & 0.54 & 1.80 & 5.00 & 1 & & & \\
\hline Leader political skills perception & 3.96 & 0.73 & 1.00 & 5.00 & $0.53^{* *}$ & 1 & & \\
\hline
\end{tabular}

$N=85$ and $n=414$. $^{*} p<0.05$ and ${ }^{* *} p<0.01$.

indicated that team task conflict was positively correlated with team performance $(r=0.30, p<0.05)$, but team relationship conflict was negatively correlated $(r=-0.21$, $p<0.05)$. Leaders' political skills were positively correlated with team task conflict $(r=0.37, p<0.01)$ and team performance $(r=0.38, p<0.05)$ but negatively correlated with team relationship conflict $(r=-0.66, p<0.01)$. Furthermore, team task conflict was negatively correlated with team relationship conflict $(r=0.21, p<0.05)$. At the individual level, team members' perceptions of their leaders' political skills were positively correlated with team members' individual performance $(r=0.53, p<0.01)$.

\subsection{Data Analysis and Hypothesis Testing}

4.2.1. Team-Individual Cross-Level Hypothesis Testing. Because team members are nested within teams, individual performance is naturally influenced by team-level variables like task or relationship conflicts, and leaders' political skills. We used a multilayer linear model (hierarchical linear modeling, HLM) to test hypotheses 1, 3, 5, and 7 .

HLM software was used to test the moderating effects of team leader political skills on the relationship between team task conflict (relationship conflict) and individual performance. First, a zero model was constructed with individual performance as the result variable to verify nesting in the model. Then, team task conflict (relationship conflict) and leaders' political skills were placed into the model for main effect analyses. The third step was to verify moderating effects by inserting interactions between team task conflict and leaders' political skills. All variables were centered before they were put into the model.

Team task conflict had a significant positive effect $(\beta=0.28, p<0.05)$ on individual performance, as shown in Model 3-1 in Table 2, where pseudo- $R^{2}$ was 0.40 , and the change was significant, so Hypothesis 1 was supported. Model 4-1 shows that the interaction between team task conflict and leadership political skills significantly enhanced individual performance $(\beta=0.18, p<0.05)$. Pseudo- $R^{2}$ was 0.33 , and the change was significant. Therefore, leaders' political skills enhanced the positive effects of team task conflict on individual performance, and Hypothesis 5 was supported. Model 3-2 shows that team relationship conflicts had a significant negative impact on individual performance $(\beta=-0.14, p<0.001)$. Pseudo- $R^{2}$ was 0.23 . The change was significant, so Hypothesis 3 was supported. Model 4-2 showed that the interaction between team relationship conflict and leader political skills had a significant effect on individual performance $(\beta=0.06, p<0.05)$. Pseudo- $R^{2}$ was 0.23 , and the change was significant. Therefore, leaders' political skills inhibited the negative effects of team relationship conflict on individual performance, and Hypothesis 7 was supported.

4.2.2. Hypothesis Testing at the Team Level. Hypotheses at the team level were tested using hierarchical regression analysis, as shown in Models 3 to 5 in Table 3. Team performance was taken as the explained variable; the control variables and team relationship conflicts at team level were put into the regression model first, and then team task conflict and team leader political skills were put into the regression model with a stepwise approach to investigate the effects of interaction items on team performance. We found that team task conflict positively affected team performance $(\beta=0.42, p<0.001)$, so Hypothesis 2 was supported.

The interaction between team task conflict and team leader political skills was significant $(\beta=0.15, p<0.05)$, and leaders' political skills enhanced the positive correlation between team task conflict and team performance: the higher the leaders' political skills, the stronger the positive impact of team task conflict on team performance. Hypothesis 6 was thus supported.

As shown in Models 4 to 6 in Table 3, we first put teamlevel control variables and team task conflicts into the regression model. Following this, we placed team relationship conflict and team leader political skills into the regression model, followed by the interaction items of team relationship conflict and team leader political skills through a stepby-step approach to investigate the effects of interaction items on team performance. We found that team relationship conflict negatively affected team performance $(\beta=-0.61, p<0.001)$, so Hypothesis 4 was supported, and the interaction between team relationship conflict and leaders' political skills was significant $(\beta=0.11, p<0.05)$. The stronger the political skills, the weaker the negative impact of team relationship conflict on performance. Hypothesis 8 was thus supported.

To more simply reflect the role of team leaders' political skills in moderating the relationship between team task or relationship conflict and team performance, a moderating effect map was drawn (Figures 2 and 3). We categorized average value of leaders' political skills at plus one and minus 
TABLE 2: Effects of leader political skills on the relationship between team conflict and individual performance.

\begin{tabular}{|c|c|c|c|c|c|c|c|}
\hline \multirow[b]{2}{*}{ Variables } & \multicolumn{7}{|c|}{ Individual performance } \\
\hline & $\begin{array}{l}\text { Model 1: zero } \\
\text { model }\end{array}$ & $\begin{array}{c}\text { Model 2-1: } \\
\text { control variables }\end{array}$ & $\begin{array}{l}\text { Model 3-1: } \\
\text { main effect }\end{array}$ & $\begin{array}{c}\text { Model 4-1: } \\
\text { interaction effect }\end{array}$ & $\begin{array}{l}\text { Model 2-2: } \\
\text { control } \\
\text { variables }\end{array}$ & $\begin{array}{l}\text { Model 3-2: } \\
\text { main effect }\end{array}$ & $\begin{array}{c}\text { Model 4-2: } \\
\text { interaction effect }\end{array}$ \\
\hline $\begin{array}{l}\text { Intercept } \gamma_{00} \\
\text { Individual } \\
\text { level }\end{array}$ & $3.80^{* * *}$ & $3.81^{* * *}$ & $3.81^{* * *}$ & $3.81^{* * *}$ & $3.81^{* * *}$ & $3.81^{* * *}$ & $3.81^{* * *}$ \\
\hline Gender & & -0.02 & -0.02 & -0.02 & -0.02 & -0.02 & -0.02 \\
\hline Tenure & & 0.04 & 0.04 & -0.04 & 0.04 & 0.04 & -0.04 \\
\hline Education & & $0.10^{*}$ & $0.10^{*}$ & $0.10^{*}$ & $0.10^{*}$ & $0.10^{*}$ & $0.10^{*}$ \\
\hline Team level & & & & & & & \\
\hline Team size & & -0.02 & -0.01 & -0.00 & -0.02 & -0.01 & -0.00 \\
\hline Team type & & -0.07 & -0.06 & -0.07 & -0.07 & -0.06 & -0.07 \\
\hline TRC & & $-1.85^{*}$ & & & & $-0.14^{* * *}$ & $-0.38^{* *}$ \\
\hline TTC & & & $0.28^{* * *}$ & $1.08^{* *}$ & $0.27^{* * *}$ & & \\
\hline LPS & & & $0.20^{* * *}$ & $0.93^{* *}$ & & $0.12^{* * *}$ & -0.05 \\
\hline TTC* LPS & & & & $0.18^{*}$ & & & \\
\hline TRC* LPS & & & & & & & $0.06^{*}$ \\
\hline$\sigma^{2}$ & 0.34 & 0.26 & 0.22 & 0.25 & 0.06 & 0.06 & 0.06 \\
\hline $\mathrm{T}$ & $0.40^{* * *}$ & $0.22^{* * *}$ & $0.24^{* * *}$ & $0.27^{* *}$ & $0.13^{* * *}$ & $0.17^{* * *}$ & $0.16^{* * *}$ \\
\hline$\chi^{2}(\mathrm{~d} f)$ & $920.72(82)$ & $1055.16(82)$ & $1021.93(82)$ & $1041.96(82)$ & $920.72(82)$ & $1075.11(82)$ & $1041.96(82)$ \\
\hline Pseudo- $R^{2}$ & & 0.45 & 0.40 & 0.33 & 0.41 & 0.23 & 0.27 \\
\hline
\end{tabular}

Notes. $N=85$ and $n=414,{ }^{*} p<0.05,{ }^{* *} p<0.01$, and ${ }^{* * *} p<0.001$. TRC: team relationship conflict; TTC: team task conflict; LPS: leader political skills.

TABLE 3: Effect of leader political skills on relationship between team conflict and team performance.

\begin{tabular}{|c|c|c|c|c|c|c|c|}
\hline \multirow{2}{*}{ Variables } & \multicolumn{7}{|c|}{ Team performance } \\
\hline & Model 1 & Model 2 & Model 3 & Variables & Model 4 & Model 5 & Model 6 \\
\hline Team size & $-0.35^{* *}$ & 0.07 & 0.67 & Team size & $-0.35^{* *}$ & 0.07 & 0.67 \\
\hline Team type & -0.11 & -0.05 & -0.23 & Team type & -0.11 & -0.05 & -0.23 \\
\hline TRC & $-0.33^{* *}$ & & & TTC & $0.30^{* *}$ & & \\
\hline TTC & & $0.42^{* * *}$ & $0.43^{* * *}$ & TRC & & $-0.61^{* * *}$ & $-0.55^{* * *}$ \\
\hline LPS & & $-0.49^{* * *}$ & $-0.31^{* * *}$ & LPS & & $-0.61^{* * *}$ & $-0.58^{* * *}$ \\
\hline TTC $*$ LPS & & & $0.15^{*}$ & TRC $*$ LPS & & & $0.11^{*}$ \\
\hline Adjusted $R^{2}$ & 0.10 & 0.71 & 0.73 & Adjusted $R^{2}$ & 0.11 & 0.53 & 0.55 \\
\hline$F$ value & $4.91^{* *}$ & $72.20^{* * *}$ & $5.05^{*}$ & $F$ value & $6.35^{* * *}$ & $37.44^{* * *}$ & $4.27^{*}$ \\
\hline$\triangle R^{2}$ & 0.13 & 0.60 & 0.02 & $\triangle R^{2}$ & 0.13 & 0.42 & 0.02 \\
\hline
\end{tabular}

Notes. $N=85$ and $n=414 .{ }^{*} p<0.05,{ }^{* *} p<0.01$, and ${ }^{* * *} p<0.001$. TRC: team relationship conflict; TTC: team task conflict; LPS: leader political skills.

one standard deviation as high political skills and low political skills, respectively. Team leaders with higher political skills (solid lines) show a steeper slope of team task conflict and team performance than that of team leaders with lower political skills (dashed lines). The slope for team relationship conflict and team performance is flat compared with that of leaders with lower political skills (dashed lines), indicating that higher political skills produce a more positive impact of team task conflict on team performance and a less negative impact of team relationship conflict on team performance. Team leaders' political skills enhanced the positive impact of team task conflict on team performance and weakened the negative impact of team relationship conflict on team performance. Hypotheses 6 and 8 were thus supported.

\section{Discussion}

This paper adopted a leader-member paired questionnaire and objective performance data from the team performance appraisal archives in green enterprises from 85 teams and corresponding 414 members to test the effects of team task conflict and relationship conflict on team and individual performance. Using leadership theory, this paper discusses the role of leaders' political skills in green enterprises in moderating the relationship between team conflict (task conflict and relationship conflict) and performance. First, we found a significant positive correlation between team task conflict and individual and team performance. This supports the results of previous research on the positive effects of task conflict on team performance [19] and expands the study of task conflict on individual performance, enriching the cross-layer theory of team task conflict, which further supports the suggestion that teamlevel interactions may impact members' individual processes and outputs [54]. Second, a significant negative correlation was found between team relationship conflict and individual and team performance. This was consistent with the conclusion of previous studies that team relationship conflict has a negative effect at the team level $[55,56]$. It was also consistent with the 


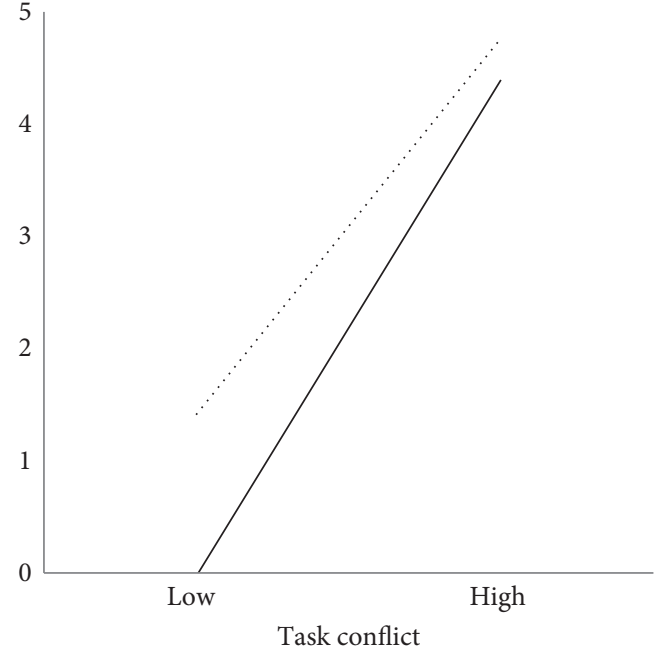

- High LPS

Figure 2: Moderating Effects of Team Leadership Political Skills on Task Conflict and Performance.

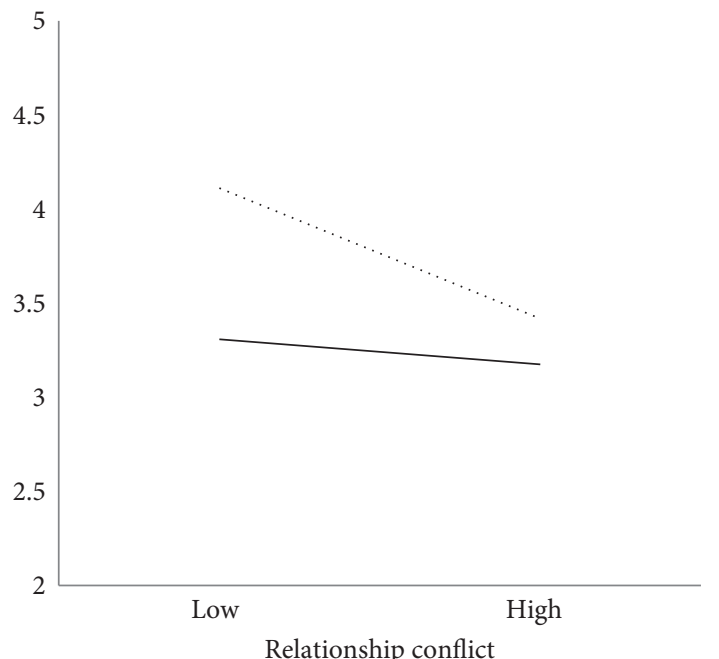

— High LPS

..... Low LPS

Figure 3: Moderating Effects of Team Leadership Political Skills on Relationship Conflict and Performance.

suggestions of Jehn and Chadwick [57] that team-level relationship conflict has a deep impact on individual-level affective and informational states, expanding the research field for relationship conflict and conducing to the expansion and deepening of cross-layer team theory [58]. Third, team leader political skills moderated the relationship between task and relationship conflict and performance at both the individual and team levels. For high leaders' political skills, the negative effect of relationship conflict on individual and team performance was significantly suppressed, and the positive effect of task conflict on individual and team performance was significantly enhanced. This result supported the conclusions of Shi and Chen [59], namely, that political skills are positively related to proactive personality and in-role performance, and it also extended the application of political skills to the team and leadership perspective, which is conducive to understanding the effectiveness of political skills more thoroughly.

The results were also in accord with a basic contention of conflict management, which proposes that a leader has an important influence on the outcomes of team conflict, such as in the leader's conflict management style and its correlation to innovation performance [13] and the relationship between teams' reactions to conflict and teams' task and social outcomes, which is moderated by transformational and emotional leadership [60]. This empirical study from green enterprises also implicated the importance of effective conflict management and the very important role of team leaders' political skills which suggested that environment leadership was positively correlated to environment culture and performance [61]. Besides, the results were consistent with the suggestions that green team resilience helped a lot in achieving environmental sustainability through green transformational leadership policy [7].

5.1. Theoretical Contributions. Overall, this study made the following theoretical contributions. First, it enriches the theory of team conflict management. Previous studies are generally limited to exploring team conflict management from situational perspectives, ignoring the leadership perspective. This study used leadership theory to study the effects of team conflict on team and individual performance, enriching team conflict theory. Second, research on team conflict has paid closer attention to its influence on team processes, and little research has been devoted to its impact on team members. In relation to the important role of team members in the implementation of green strategy, this study enriched multilevel team theory in green enterprises by discussing the boundaries of team conflict. It deepened the understanding of two types of team conflict in theory while also providing theoretical guidance for team conflict management and practical leaders' political skills training. Third, this study proposed effective ways for green enterprises to improve performance from the microperspective of internal team conflict management based on leadership theory, which expands and enriches the research on green enterprises performance. The previous studies on green enterprise performance were almost based on theories like institutional innovation and ecological civilization from the macroperspectives. However, the lack of research on the microlevel of the organization is obviously not appropriate because the individual in the enterprise and the team composed of individuals are the ultimate value source of green enterprises.

5.2. Managerial Contributions. Team conflict management in green enterprises requires further attention. To promote the internal systems innovation and sustainable development in green enterprises, team conflict must be reduced to its lowest possible level. Improving the effectiveness of team conflict management plays an important role in the optimization of team processes and team performance improvement. However, not all team conflicts have a negative impact on team management, nor are all of the consequences of team conflicts directly related. It is possible that 
team conflicts are only a phenomenon whose real cause must be seriously investigated. Therefore, the management of team conflict by team managers should go beyond distinguishing different types of team conflict and exploring the deep reasons behind the conflict to improve the effectiveness of team conflict management. Green development has become the theme of the times. The green transformation of the entire green enterprises indicates that team conflict can be an inevitable problem. Organization and team conflict management in green enterprises should be highly valued by managers in green enterprise, and they should try their best to reduce the negative effects of team conflict and take advantage of its positive effects. Green enterprises should realize the benign interaction in organizations and teams, achieve the unity of short-term interests and long-term development, and realize the sustainable development of green enterprises.

Green enterprises should look rationally at team conflicts. The development of such enterprises incorporates the promotion of green production, the provision of green products, the implementation of green marketing strategies, the shaping of green culture, and other tasks. It is a complex unit, composed of many stakeholders. It is possible that this is not the best conflict management scheme for reducing relationship conflict and increasing task conflict. In some cases, managers may consider upgrading conflict management by upgrading team leaders' political skills. Effective leadership practices help minimize the negative role of relationship conflict and maximize the positive role of task conflict.

Finally, attention should be paid to the training of political skills in team leadership. The implementation and development of green strategies in green enterprises require strong leadership. Team leaders play an important role in promoting orderly team management, alleviating negative team conflicts, creating a positive team work atmosphere, and improving team performance. To improve the level of team conflict management and team performance, the political skills training of team leaders must be strengthened.

5.3. Limitations and Opportunities for Future Research. There were some limitations in this study. First, the theoretical model and empirical testing were applied only at two levels, those of the team and individual. However, a team is a multilayer nesting system whose organization may play an important role in team conflict management and performance improvement. Studying the mechanism and effects of team conflict management using a three-level model will be of great significance. Second, the sample of this paper was concentrated on green enterprises, so the conclusions may have had some limitations in terms of its universality and generalizability. In future research, we hope to investigate other industries to improve the external validity of the results and create management suggestions that are more practical and instructive. Third, due to the limitations of the research goal and the length of the paper, the relationships among the multiple variables involved in the theoretical model of this study were not examined. For example, team task conflict may have had a certain impact on team relationship conflict, which should be investigated in future research. This factor would likely not fundamentally alter the findings in the current study; it should be incorporated in future research to improve the accuracy of the findings.

\section{Data Availability}

Empirical data were collected from 85 dyads of leaders and team members in 36 green enterprises in China. The questionnaire data used to support the findings of this study are included within the supplementary information files. Anyone who wants to get the data can contact the corresponding author at e-mail: eric_zhang@hnu.edu.cn.

\section{Conflicts of Interest}

The authors declare that they have no conflicts of interest.

\section{Acknowledgments}

This research was supported by Humanities and Social Sciences Research Project of the Ministry of Education of China (Grant 20YJC630137), Education Department Excellent Youth Project of Hunan Province (Grant 19B144), and Natural Science Foundation of Hunan Province (Grant 2019JJ40074).

\section{Supplementary Materials}

The supplementary files consist of data at two different levels in the same green enterprises. Data at team level is composed of four main variables and two control variables. TRC means team relationship conflict and TTC means team task conflict, which are the independent variables at team level; LPS means leader political skills and TP means team performance, which denote the moderating variable and dependent variable at team level, respectively. Team type and team size are both control variables at team level. Data at individual level is composed of one main variable and three control variables. IP means individual performance, which denotes the dependent variable at individual level. Gender, tenure, and education are all control variables at individual level. In order to establish a one-to-one relationship, we put a number on each team and individual. (Supplementary Materials)

\section{References}

[1] D. Dang, "Can environmental subsidies promote the green investment of enterprises?" Modern Economy, vol. 11, no. 1, pp. 109-125, 2020.

[2] P. Shapira, A. Gök, E. Klochikhin, and M. Sensier, "Probing "green" industry enterprises in the UK: a new identification approach," Technological Forecasting and Social Change, vol. 85, pp. 93-104, 2014.

[3] S. Mi, "Integrated intelligent green scheduling of predictive maintenance for complex equipment based on information services," IEEE Access, vol. 8, pp. 45797-45812, 2020. 
[4] L. I. Cuixia, G. E. Yanan, and B. Ge, "Issues concerning "greenification" of green food enterprises," Asian Agricultural Research, vol. 5, no. 5, pp. 7-12, 2013.

[5] W. Zhang, M. Zhang, W. Zhang, Q. Zhou, and X. Zhang, "What influences the effectiveness of green logistics policies? A grounded theory analysis-ScienceDirect," Science of The Total Environment, vol. 714, Article ID 136731, 2020.

[6] C. K. W. De Dreu and L. R. Weingart, "Task versus relationship conflict, team performance, and team member satisfaction: a meta-analysis," Journal of Applied Psychology, vol. 88, no. 4, p. 741, 2003.

[7] S. Op, V. O. Olorunsola, and U. V. Alola, "Achieving environmental sustainability through green transformational leadership policy: can green team resilience help?" Business Strategy and the Environment, vol. 9, pp. 1-12, 2020.

[8] G. Orsatti and M. Pezzoni, "The antecedents of green technologies: the role of team-level recombinant capabilities," Research Policy, vol. 49, pp. 1-17, 2020.

[9] Wei, "How do individual-level factors affect the creative solution formation process of teams?" Creativity \& Innovation Management, vol. 24, no. 3, pp. 508-524, 2015.

[10] A. C. Amason, "Distinguishing the effects of functional and dysfunctional conflict on strategic decision making: resolving a paradox for top management teams," Academy of Management Journal, vol. 39, no. 1, pp. 123-148, 1996.

[11] Y. Tu, "Team ability disparity and goal interdependence influence team members' affective and informational states," Group Dynamics Theory Research and Practice, vol. 24, no. 1, pp. 4-25, 2020.

[12] J. C. Huang, "Unbundling task conflict and relationship conflict," International Journal of Conflict Management, vol. 21, no. 3, pp. 334-355, 2010.

[13] J. Yin, M. Jia, Z. Ma, and G. Liao, “Team leader's conflict management styles and innovation performance in entrepreneurial teams," International Journal of Conflict Management, vol. 31, no. 3, pp. 373-392, 2020.

[14] W. Zhang, S. L. Sun, Y. Jiang, and W. Zhang, "Openness to experience and team creativity: effects of knowledge sharing and transformational leadership," Creativity Research Journal, vol. 31, no. 1, pp. 62-73, 2019.

[15] A. C. Amason, "The effects of top management team size and interaction norms on cognitive and affective conflict," Journal of Management, vol. 23, no. 4, pp. 495-516, 1997.

[16] A. P. Sapienza, J. M. Dukerich, and J. M. Dukerich, "Leadership, team building, and team member characteristics in high performance Project teams," Engineering Management Journal, vol. 14, no. 4, pp. 3-10, 2002.

[17] S. A. Fonseca and C. J. Chiappetta Jabbour, "Assessment of business incubators' green performance: a framework and its application to Brazilian cases," Technovation, vol. 32, no. 2, pp. 122-132, 2012.

[18] K. A. Jehn, "A multimethod examination of the benefits and detriments of intragroup conflict," Administrative Science Quarterly, vol. 40, no. 2, pp. 256-282, 1995.

[19] G. Todorova, M. R. W. Brake, and L. R. Weingart, "Work design and task conflict in interdisciplinary groups," International Journal of Conflict Management, vol. 31, no. 4, pp. 623-646, 2020.

[20] E. Weldon, K. A. Jehn, and P. Pradhan, "Processes that mediate the relationship between a group goal and improved group performance," Journal of Personality and Social Psychology, vol. 61, no. 4, pp. 555-569, 1991.
[21] L. L. Putnam, "Productive conflict: negotiation as implicit coordination," International Journal of Conflict Management, vol. 5, no. 3, pp. 284-298, 1994.

[22] C. M. Fiol, "Consensus, diversity, and learning in organizations," Organization Science, vol. 5, no. 3, pp. 403-420, 1994.

[23] D. Tjosvold, P. Wu, and Y. F. Chen, "The effects of collectivistic and individualistic values on conflict and decision making: an experiment in China," Journal of Applied Social Psychology, vol. 40, no. 11, pp. 2904-2926, 2010.

[24] H. Gibbons and J. Stahl, "ERP predictors of individual performance on a prospective temporal reproduction task," Psychological Research, vol. 72, no. 3, pp. 311-320, 2008.

[25] J. R. Hackman and J. Richard, "Leading teams," Team Performance Management: An International Journal, vol. 10, no. 3/4, pp. 84-88, 2004.

[26] G. L. Stewart, "A meta-analytic review of relationships between team design features and team performance," Journal of Management, vol. 32, no. 1, pp. 29-55, 2006.

[27] I. L. Janis, Groupthink, Houghton Mifflin, Boston, MA, USA, 1982.

[28] A. C. Amason and D. M. Schweiger, "Resolving the paradox of conflict, strategic decision making, and organizational performance," International Journal of Conflict Management, vol. 5, no. 3, pp. 239-253, 1994.

[29] F. R. C. de Wit, L. L. Greer, and K. A. Jehn, "The paradox of intragroup conflict: a meta-analysis," Journal of Applied Psychology, vol. 97, no. 2, pp. 360-390, 2012.

[30] T. L. Simons and R. S. Peterson, "Task conflict and relationship conflict in top management teams: the pivotal role of intragroup trust," Journal of Applied Psychology, vol. 85, no. 1, pp. 102-111, 2000.

[31] B. M. Staw, L. E. Sandelands, and J. E. Dutton, "Threat rigidity effects in organizational behavior: a multilevel analysis," Administrative Science Quarterly, vol. 26, no. 4, pp. 501-524, 1981.

[32] H. C. Ellis and P. W. Ashbrook, "The "state" of mood and memory research: a selective review," Journal of Social Behavior \& Personality, vol. 4, no. 2, pp. 1-21, 1989.

[33] G. A. Van Kleef, C. K. W. De Dreu, A. S. R. Manstead, and A. S. R. Manstead, "The interpersonal effects of anger and happiness in negotiations," Journal of Personality and Social Psychology, vol. 86, no. 1, pp. 57-76, 2004.

[34] O. Janssen, E. Van De Vliert, and C. Veenstra, "How task and person conflict shape the role of positive interdependence in management teams," Journal of Management, vol. 25, no. 2, pp. 117-141, 1999.

[35] K. A. Jehn, G. B. Northcraft, and M. A. Neale, "Why differences make a difference: a field study of diversity, conflict, and performance in workgroups," Administrative Science Quarterly, vol. 44, no. 4, pp. 741-763, 1999.

[36] D. C. Treadway, "Political will, political skill, and political behavior," Journal of Organizational Behavior, vol. 26, no. 26, pp. 229-245, 2005.

[37] D. C. Treadway, W. A. Hochwarter, G. R. Ferris et al., "Leader political skill and employee reactions," The Leadership Quarterly, vol. 15, no. 4, pp. 493-513, 2004.

[38] C. Douglas and A. P. Ammeter, "An examination of leader political skill and its effect on ratings of leader effectiveness," The Leadership Quarterly, vol. 15, no. 4, pp. 537-550, 2004.

[39] P. S. Deortentiis, "Cohesion and satisfaction as mediators of the team trust-team effectiveness relationship," Career Development International, vol. 18, no. 5, pp. 521-543, 2013.

[40] d. C. K. W. Dreu, "When too little or too much hurts: evidence for a curvilinear relationship between task conflict and 
innovation in teams," Journal of Management, vol. 32, no. 1, pp. 83-107, 2006.

[41] S. Liu, J. Hu, Y. Li, Z. Wang, and X. Lin, "Examining the crosslevel relationship between shared leadership and learning in teams: evidence from China," The Leadership Quarterly, vol. 25, no. 2, pp. 282-295, 2014.

[42] S. Groover and R. Gotian, "Five "power skills" for becoming a team leader," Nature, vol. 577, no. 7792, pp. 721-722, 2020.

[43] B. A. D. Jong and E. Tom, "How does trust affect the performance of ongoing teams? The mediating role of reflexivity, monitoring, and effort," Academy of Management Journal, vol. 53, no. 3, pp. 535-549, 2010.

[44] J. A. Moss and J. E. Barbuto, "Testing the relationship between interpersonal political skills, altruism, leadership success and effectiveness: a multilevel model," Contract Management, vol. 11, no. 2, p. 155, 2010.

[45] M. Harvey and M. M. Novicevic, "The development of political skill and political capital by global leaders through global assignments," The International Journal of Human Resource Management, vol. 15, no. 7, pp. 1173-1188, 2004.

[46] Kathleen, "Leader political skill and team performance," Journal of Management, vol. 30, no. 3, pp. 309-327, 2004.

[47] N. Ouedraogo, M. L. Ouakouak, and Z. Mahamadou, "The effects of political skills on leader effectiveness and change outcome," Academy of Management Proceedings, vol. 2020, no. 1, p. 21229, 2020.

[48] K. K. Ahearn, G. R. Ferris, W. A. Hochwarter, C. Douglas, and A. P. Ammeter, "Leader political skill and team performance," Journal of Management, vol. 30, no. 3, pp. 309-327, 2004

[49] R. W. Brislin, "Back-translation for cross-cultural research," Journal of Cross-Cultural Psychology, vol. 1, no. 3, pp. 185-216, 1970.

[50] K. A. Jehn and C. Bendersky, "Intragroup conflict in organizations: a contingency perspective on the conflict-outcome relationship," Research in Organizational Behavior, vol. 25, pp. 187-242, 2003.

[51] G. R. Ferris, D. C. Treadway, R. W. Kolodinsky et al., "Development and validation of the political skill inventory," Journal of Management, vol. 31, no. 1, pp. 126-152, 2005.

[52] L. R. James, R. G. Demaree, and G. Wolf, "Estimating withingroup interrater reliability with and without response bias," Journal of Applied Psychology, vol. 69, no. 1, pp. 85-98, 1984.

[53] J. M. George and K. Bettenhausen., "Understanding prosocial behavior, sales performance, and turnover: a group-level analysis in a service context," Journal of Applied Psychology, vol. 75, no. 6, pp. 698-709, 1990.

[54] W. Watson, D. Cooper, M. A. J. L. N. Torres, and N. G. Boyd, "Team processes, team conflict, team outcomes, and gender: an examination of U.S. and Mexican learning teams," International Journal of Intercultural Relations, vol. 32, no. 6, pp. 524-537, 2008.

[55] N. Gamero, V. González-Romá, J. M. Peiró, and Peiró, “The influence of intra-team conflict on work teams' affective climate: a longitudinal study," Journal of Occupational and Organizational Psychology, vol. 81, no. 1, pp. 47-69, 2008.

[56] M.-H. Chen, "Understanding the benefits and detriments of conflict on team creativity process," Creativity and Innovation Management, vol. 15, no. 1, pp. 105-116, 2006.

[57] K. A. Jehn, C. Chadwick, and S. M. B. Thatcher, "To agree or not to agree: the effects of value congruence, individual demographic dissimilarity, and conflict on workgroup outcomes," International Journal of Conflict Management, vol. 8, no. 4, pp. 287-305, 1997.
[58] V. Rousseau, C. Aubé, and A. Savoie, "Teamwork behaviors," Small Group Research, vol. 37, no. 5, pp. 540-570, 2006.

[59] J. Shi, Z. Chen, and L. Zhou, "Testing differential mediation effects of sub-dimensions of political skills in linking proactive personality to employee performance," Journal of Business and Psychology, vol. 26, no. 3, pp. 359-369, 2010.

[60] O. B. Ayoko and V. J. Callan, "Teams' reactions to conflict and teams' task and social outcomes: the moderating role of transformational and emotional leadership," European Management Journal, vol. 28, no. 3, pp. 220-235, 2010.

[61] C. Pan and Tianhong, "Environmental leadership, green organization recognition and enterprise green innovation performance," Chinese Journal of Management, vol. 14, no. 6, pp. 832-841, 2017. 